\title{
What Is the Best Strategy for Enhancing the Effects of Topically Applied Ozonated Oils in Cutaneous Infections?
}

\author{
I. Zanardi, ${ }^{1}$ S. Burgassi, ${ }^{2}$ E. Paccagnini, ${ }^{3}$ M. Gentile, ${ }^{3}$ V. Bocci, ${ }^{4}$ and V. Travagli ${ }^{1}$ \\ ${ }^{1}$ Dipartimento di Biotecnologie, Chimica e Farmacia, Università degli Studi di Siena, 53100 Siena, Italy \\ ${ }^{2}$ Dipartimento di Medicina Molecolare e dello Sviluppo, Università degli Studi di Siena, 53100 Siena, Italy \\ ${ }^{3}$ Dipartimento di Scienze della Vita, Università degli Studi di Siena, 53100 Siena, Italy \\ ${ }^{4}$ Dipartimento di Fisiologia, Università degli Studi di Siena, 53100 Siena, Italy
}

Correspondence should be addressed to V. Travagli; travagli@unisi.it

Received 12 April 2013; Accepted 21 September 2013

Academic Editor: Gulam Waris

Copyright (C) 2013 I. Zanardi et al. This is an open access article distributed under the Creative Commons Attribution License, which permits unrestricted use, distribution, and reproduction in any medium, provided the original work is properly cited.

\begin{abstract}
Owing to diabetes, atherosclerosis, and ageing, there are several million patients undergoing skin lesions degenerated into infected ulcers with very little tendency to heal and implying a huge socioeconomical cost. Previous medical experience has shown that the daily application of ozonated oil eliminates the infection and promotes a rapid healing. The purpose of the study is the optimization of the antimicrobial effect of ozonated oils by testing in vitro four bacterial species and one yeast without or in the presence of different amounts of human serum. The results obtained suggest that a gentle and continuous removal of debris and exudate is an essential condition for the potent bactericidal effect of ozonated oils. In fact, even small amounts of human serum inactivate ozone derivatives and protect bacteria. The application of ozonated oil preparations is very promising in a variety of skin and mucosal infections. Moreover, ozonated oils are far less expensive than antibiotic preparations.
\end{abstract}

\section{Introduction}

There is a general convincement that ozone is one of the best compounds for killing bacteria, viruses, and parasites present in either dirty water or in prospectively useful drinking water [1-3], as well as against biofilms [4]. Although this is true, it has led to the assumption that intravenous injection of a gas mixture composed of oxygen $\left(\mathrm{O}_{2}, \geq 95 \%\right)$ and ozone $\left(\mathrm{O}_{3}, \leq 5 \%\right)$ in both bacterial sepsis and HIV patients will inactivate the pathogens and cure the diseases. Such a concept is wrong because it naively supposes that pathogens will be destroyed like those present in water, and in fact, the intravenous administration of $\mathrm{O}_{2}-\mathrm{O}_{3}$ has been prohibited because it is ineffective and prone to kill patients with $\mathrm{O}_{2}$ embolism [5]. On the other hand, during ozonated autohemotherapy $\left(\mathrm{O}_{3}\right.$-AHT), ozone dissolves tenfold more than oxygen in the water of serum, but owing to the potent antioxidant capacity due to the presence of hydrophilic (uric acid, ascorbic acid, GSH, free Cysteine, and albumin) and lipophilic (vitamin E, bilirubin, thioredoxin, and $\alpha$-lipoic acid) compounds, it is partly neutralized, while the bulk immediately reacts with n-3 and n-6 polyunsaturated fatty acids (PUFA) generating its crucial messengers: hydrogen peroxide $\left(\mathrm{H}_{2} \mathrm{O}_{2}\right)$ and active aldehydes, mainly 4-hydroxy2,3-trans-nonenal (4-HNE) [6]. Consequently, ozone having in blood an extremely short life cannot oxidize pathogens either free in exudates or intracellular because they are well protected by the serum and cellular antioxidants. Our previous paper [7] clarified that even the addition of only $5 \%$ human serum to the bacterial suspensions allowed bacterial survival in comparison to samples in saline tested with the same gaseous ozone concentration and time exposure. Such a result is important, and so far, it has been overlooked.

Even at the risk of denaturing sensitive proteins, at least a partial disinfection of human serum can be performed in vitro with very high ozone concentrations. However, such conditions are not usable on the whole blood because of inherent blood cell damage. At the therapeutic range of both useful and safe ozone concentration for performing $\mathrm{O}_{3}$-AHT, the maximal $\mathrm{H}_{2} \mathrm{O}_{2}$ concentration can be about $40 \mu \mathrm{M}$, but it cannot display bactericidal activity because it has a half time less than $1 \mathrm{~min}$ and a very fast dilution into the intracellular 
TABLE 1: Chemical-physical characterization of the various samples (see text for further details).

\begin{tabular}{|c|c|c|c|c|c|}
\hline \multirow{2}{*}{ Sample } & \multirow{2}{*}{$\mathrm{PV}(\mathrm{mEq} / 1,000 \mathrm{~g})$} & \multirow{2}{*}{$\mathrm{AV}(\mathrm{mg} \mathrm{KOH} / \mathrm{g})$} & \multirow{2}{*}{ IV (g/100 g) } & \multicolumn{2}{|c|}{ Viscosity $(\mathrm{mPa} \cdot \mathrm{s})$} \\
\hline & & & & $22^{\circ} \mathrm{C}$ & $35^{\circ} \mathrm{C}$ \\
\hline $\mathrm{SO}$ & $198 \pm 9$ & $0.70 \pm 0.01$ & $113.65 \pm 1.50$ & $59.9 \pm 1.1$ & $34.2 \pm 0.3$ \\
\hline OSO low & $949 \pm 33$ & $1.67 \pm 0.08$ & $96.05 \pm 3.53$ & $84.9 \pm 0.7$ & $48.1 \pm 0.4$ \\
\hline OSO middle & $1631 \pm 64$ & $2.45 \pm 0.05$ & $81.32 \pm 2.98$ & $116 \pm 1$ & $64.5 \pm 0.2$ \\
\hline OSO high & $3170 \pm 101$ & $7.32 \pm 0.20$ & $57.21 \pm 2.34$ & $248 \pm 2$ & $129 \pm 2$ \\
\hline
\end{tabular}

PV: peroxide value; $\mathrm{AV}$ : acidity value; IV: iodine value.

water of blood cells. These data justify the very modest activity of $\mathrm{O}_{3}$-AHT in bacterial and viral septic patients, not due to a direct anti-infective effects, but to a slightly enhanced immune activity elicited by the production of interferon and other cytokines induced by $\mathrm{H}_{2} \mathrm{O}_{2}$ in lymphomonocytes [8].

On the other hand, the direct ozonation of vegetable oils with unsaturated fatty acids leads to the formation of the 1,2,4-trioxolane moiety $[9,10]$, which represents the active form of ozone in these substrates. The trioxolane ring within the vegetable ozonated matrices quickly generates some compounds responsible for the healing process when applied in either a humid wound or an ulcer [11-14]. Moreover, it is accountable for antimicrobial and antimycotic treatments [15-17]. All these effects occur in the absence of cutaneous adverse reactions.

The main object of the present paper has been to clarify the antibacterial effectiveness of ozonated oils in mucosal and cutaneous infected wounds and ulcers which interest millions of patients who experience great discomfort and a relevant social-economic cost. Nonetheless, even in such a case, there is caveat because wounds and ulcers are always accompanied with an infection implying the presence of exudates comprising serum proteins, hence antioxidants, which may limit the efficacy of the ozonated oil. Sesame oil was selected for its wide use in pharmaceuticals as well as for its chemical compositions in terms of unsaturated fatty acids, with a balance between oleic and linoleic acid [12].

\section{Materials and Methods}

2.1. Materials. Chemicals were purchased from SigmaAldrich and used without further purification. In particular, the sesame oil (SO) was obtained from the seeds of Sesamum indicum (batch number S3547).

2.2. Ozonated Oil. SO was treated as reported in Sega et al. [10] in order to obtain the ozonated sesame oil (OSO) samples. Briefly, $\mathrm{O}_{3} / \mathrm{O}_{2}$ mixture was bubbled for different times in Drechsel bottles containing $40 \mathrm{~mL}$ of sesame oil, leading to different $\mathrm{O}_{3}$ amounts. The $\mathrm{O}_{3}$ flow-rate was kept constant at $1.5 \mathrm{~L} /$ minutes in all the experiments, and $\mathrm{O}_{3}$ concentration as evaluated in the feed gas was $45 \mathrm{mg} / \mathrm{L}$. Chemical characterizations (namely, PV, peroxide value; AV, acidity value; IV, iodine value) of OSO samples have been performed. As for PV evaluation, it was determined by means of iodometric titration placing the sample at reflux for 60 minutes [18]. According to the PV, OSO has been classified as low (1-OSO), medium (m-OSO), and high (h-OSO). Viscosity measurements (Viscomate VM-10AL, CBC Europe) have been also performed by at both the temperatures of 22 and $35 \pm 0.2^{\circ} \mathrm{C}$. In Table 1 , the physical-chemical characterization of the various test compounds is specified.

\subsection{Microorganism Strains, Sample Preparations, and Culture} Conditions. The reference strains of Staphylococcus aureus (ATCC25923), Enterococcus faecalis (clinical isolate), Pseudomonas aeruginosa (ATCC27853), Escherichia coli (ATCC25922), and Candida albicans (ATCC90028) used for this study were purchased from Oxoid.

On the basis of preliminary experiments, the evaluation of the antibacterial activity of OSO has been done either at $10^{7} \mathrm{CFU} \mathrm{mL}^{-1}$ or $10^{4} \mathrm{CFU} \mathrm{mL}^{-1}$ bacterial concentrations.

For the first line of experiments (microorganisms in contact with OSO at different content of peroxides), microorganisms from an overnight culture in tryptic soy agar (Oxoid) were suspended (density of $0.5 \mathrm{McF}$ arland standard) in buffered physiological solution $\mathrm{pH} 7.4$ (denominated saline) with Tween $80(2 \%)$ and diluted in order to obtain about $10^{7} \mathrm{CFU} \mathrm{mL} \mathrm{m}^{-1}$. The addition of Tween 80 is indispensable for achieving a stable emulsion of oil in saline, and it is compatible with the microbial growth [19]. The samples were subdivided $(5 \mathrm{~mL})$ and introduced in centrifuge tubes containing different amounts ( 25 or $50 \mathrm{mg}$ ) of the oils (1-OSO; $\mathrm{m}$-OSO; h-OSO) under investigation.

For the second line of experiments (microorganisms in contact with h-OSO in the presence of different serum concentrations), microorganisms from an overnight culture in tryptic soy agar (Oxoid) were suspended (density of 0.5 McFarland standard) in buffered physiological solution $\mathrm{pH}$ 7.4 (denominated saline) with Tween 80 (2\%) and diluted in order to obtain about $10^{4} \mathrm{CFU} \mathrm{mL} \mathrm{m}^{-1}$ in the presence of different serum concentrations $(0 ; 5 \% ; 10 \%)$. The samples were subdivided $(5 \mathrm{~mL})$ and introduced in centrifuge tubes containing $100 \mathrm{mg}$ of sample oil, h-OSO.

In both experiments, the centrifuge tubes were shaken for 6 hours. For each treatment, $100 \mu \mathrm{L}$ was removed at different time intervals (1, 3, and 6 hours) from the tube and incubated for $24-48 \mathrm{~h}$ at $36^{\circ} \mathrm{C}$. For each exposure time, the average number of colonies from treated plates was divided by the number of colonies from control plates to obtain a percentage viability value. Each treatment was repeated at least five times $(\mathrm{CV} \%<5)$. 
TABLE 2: Viability (\%) of the different strains as obtained with respect to control (microbial count in the presence of the corresponding amount of SO; see text for further details).

\begin{tabular}{|c|c|c|c|c|c|c|c|}
\hline \multirow{2}{*}{ Type } & \multirow{2}{*}{ Treatment time } & \multicolumn{3}{|c|}{$25 \mathrm{mg}$ OSO/5 mL of microorganism suspension } & \multicolumn{3}{|c|}{$50 \mathrm{mg} \mathrm{OSO} / 5 \mathrm{~mL}$ of microorganism suspension } \\
\hline & & 1-OSO & $\mathrm{m}-\mathrm{OSO}$ & h-OSO & $1-\mathrm{OSO}$ & $\mathrm{m}-\mathrm{OSO}$ & h-OSO \\
\hline \multirow{3}{*}{ S. aureus } & $1 \mathrm{~h}$ & 65 & 58 & 58 & 57 & 47 & 47 \\
\hline & $3 \mathrm{~h}$ & 20 & 21 & 0.2 & 1 & 3.6 & 0.2 \\
\hline & $6 \mathrm{~h}$ & 0 & 0 & 0 & 0 & 0 & 0 \\
\hline \multirow{3}{*}{ P. aeruginosa } & $1 \mathrm{~h}$ & 100 & 100 & 100 & 100 & 100 & 25 \\
\hline & $3 \mathrm{~h}$ & 100 & 100 & 5.7 & 13.7 & 15.1 & 2 \\
\hline & $6 \mathrm{~h}$ & 5 & 5 & 0 & 1.8 & 3.8 & 0 \\
\hline \multirow{3}{*}{ E. faecalis } & $1 \mathrm{~h}$ & 100 & 100 & 100 & 100 & 100 & 100 \\
\hline & $3 \mathrm{~h}$ & 100 & 100 & 100 & 100 & 27 & 23 \\
\hline & $6 \mathrm{~h}$ & 20 & 15 & 0.1 & 7 & 0.1 & 0 \\
\hline \multirow{3}{*}{ E. coli } & $1 \mathrm{~h}$ & 100 & 100 & 100 & 100 & 100 & 100 \\
\hline & $3 \mathrm{~h}$ & 0.8 & 0.8 & 0.5 & 0.4 & 0.4 & 0.4 \\
\hline & $6 \mathrm{~h}$ & 0.4 & 0.4 & 0 & 0.3 & 0.2 & 0 \\
\hline \multirow{3}{*}{ C. albicans } & $1 \mathrm{~h}$ & 100 & 100 & 100 & 100 & 100 & 100 \\
\hline & $3 \mathrm{~h}$ & 39 & 38 & 18 & 13 & 13 & 0.2 \\
\hline & $6 \mathrm{~h}$ & 1.6 & 0 & 0 & 0 & 0 & 0 \\
\hline
\end{tabular}

2.4. SEM Characterization. The morphology of microorganisms before and after oil treatment (first line experiment, after six hours) was investigated by Scanning Electron Microscopy (SEM) studies. A drop of liquid cell suspension was placed on poly-l-lysine treated glass coverslip for five minutes. Then, the coverslip was fixed for immersion in a $2.5 \%$ glutaraldehyde solution in phosphate buffer $0.1 \mathrm{M} \mathrm{pH} 7.2$ (PB) for 2 hours at $4^{\circ} \mathrm{C}$, washed in $\mathrm{PB}$, postfixed in $1 \% \mathrm{OsO} 4$ in $\mathrm{PB}$ for $30 \mathrm{~min}$. at $4^{\circ} \mathrm{C}$, dehydrated in ascending alcohol series, incubated for three times in tert-butanol, and finally freeze dried. Afterwards, the coverslip was mounted on aluminum stub, coated with $20 \mathrm{~nm}$ gold in Balzers MED 010 sputtering device, and observed in Philips XL20 scanning electron microscope at $20 \mathrm{kV}$.

2.5. Statistical Analysis. Results were obtained from at least five independent measurements and expressed as the mean \pm $\mathrm{SD}$, unless otherwise stated. Statistical evaluations were performed by a one-way analysis of variance (ANOVA) using a statistics software (InStat software, version 3.0, GraphPAD Software Inc., San Diego, CA). Bonferroni test was employed after ANOVA to evaluate statistical difference between individual means. Significance was defined as a $P$ value of less than 0.05 .

\section{Results}

Table 2 shows the bactericidal effect with respect to time $(1,3$, and $6 \mathrm{~h}$ ) of different amounts $(25 \mathrm{mg}$ and $50 \mathrm{mg}$ ) of 1-OSO, m-OSO, and h-OSO dispersed in the bacterial suspensions at about $10^{7} \mathrm{CFU} \mathrm{mL}^{-1}$. As it was expected, it has been possible to observe a concentration-dependent disinfectant trend. However, differences in behavior between the various strains tested at the different experimental conditions have been detected. In detail, no viable bacteria were obtained only after six hours and at the maximum peroxide content of the ozonated oils, except in the case of the less amount of OSO for E. faecalis that appeared to be the most resistant strain. Considering all the data, also $P$. aeruginosa and, to a lesser extent, C. albicans were quite resistant. On the contrary, $S$. aureus appeared to be the most sensitive one, with a sensible growth diminution since after the first hour with the minimum content of both ozonated oil and peroxide content. As regards E. coli, after three hours, a marked sensitivity to treatment has been observed, regardless of the amount of the ozonated oil.

In order to have more information on the mechanism of degradation, S.E.M. investigation has been performed [20], and the results are shown in Figure 1. As it is possible to observe, both bacterial and C. albicans cells maintained intact shapes and size, just after ozonated oil exposition. Also the surface morphology of the cells was unaltered with respect to untreated ones, as well as the number of damaged cells. The only exception occurred at cellular surface of $P$. aeruginosa where the cells showed a rough outside with the appearance of tiny bumps similar to small vesicles, after contact with ozonated oil (Figure 1, arrowheads).

Moreover, to simulate the in vivo conditions of application of the ozonated oils and to evaluate both if and how much the presence of cutaneous infection exudates can compromise the ozonated oil efficacy, the bactericidal effect with respect to time $(1,3$, and $6 \mathrm{~h}$ ) of $100 \mathrm{mg}$ of $\mathrm{h}$-OSO dispersed in the bacterial suspensions at about $10^{4} \mathrm{CFU} \mathrm{mL}^{-1}$ either in the absence or in the presence of serum at different concentrations $(2.5 \%, 5 \%$, and $10 \%)$ has been studied. For completeness' 

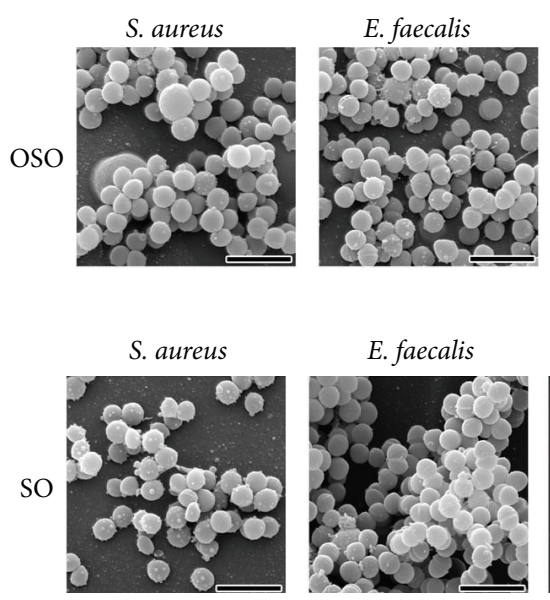

E. faecalis

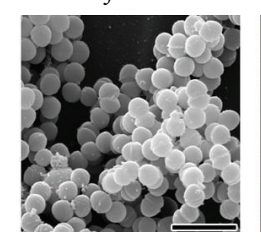

P. aeruginosa

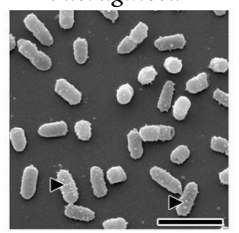

(a)

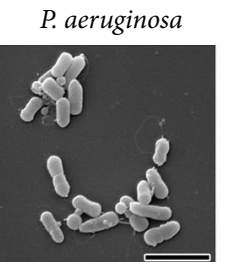

(b)
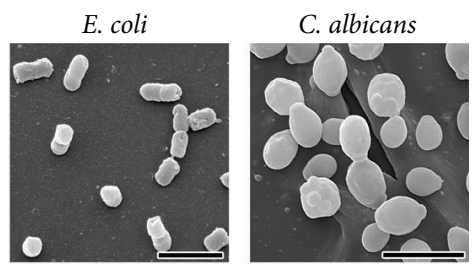

E. coli

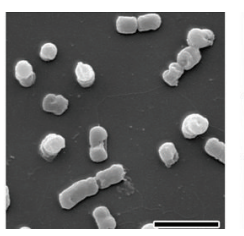

C. albicans

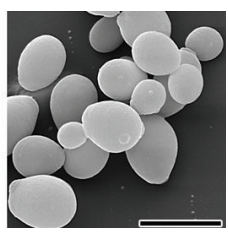

FIGURE 1: Scanning electron micrographs of the surface morphology of the cells after contact with either ozonated sesame oil (a) or sesame oil as control (b). Scale bars correspond to $2 \mu \mathrm{m}$, except for Candida albicans ( $5 \mu \mathrm{m})$. Arrowheads show small vesicles on cellular surface of Pseudomonas aeruginosa (see text for further details).

sake, blood and plasma are unsuitable to be tested because in the presence of bacterial suspensions they tend to coagulate. On the contrary, human serum while having a comparable amount of antioxidants does not present these drawbacks.

As previously stated, the in vitro use of SO and its derivatives needs the emulsification with a surfactant, like the nonionic one Tween 80 . Such experimental conditions have been calibrated after preliminary tests in order to obtain the best antibacterial effect against E. faecalis in the presence of about $10^{4} \mathrm{cfu} / \mathrm{mL}$, assuming that such a quantity corresponds to $10^{7} \mathrm{cfu} / \mathrm{g}$ of infected cutaneous lesions [21].

Figure 2 shows that the presence of human serum as low as $2.5 \%$ increased microorganism survival even at higher concentration of the oil at the higher peroxide content, indicating the role of protective biomolecules as antioxidants present in serum. Moreover, the bacterial viability totally remained when samples have been added with $10 \%$ of fresh serum (data not shown). However, in patients after the appropriate elimination of exudates, the ozonated $\mathrm{SO}$ is charged every 12 hours, and its therapeutic activity is likely to be more effective. We are planning to evaluate the effect of such ozone derivatives in vivo in a clinical trial.

\section{Discussion}

It is known that ulcers with scarce tendency to heal are due to a local hypoxic situation, presence of bacteria, minimal cell proliferation, and a reduced production of extracellular matrix. In our experience, by using the ozonated oil in vivo, the "restitutio ad integrum" including the final healing and scar tissue remodeling takes much less time in elderly and/or diabetic patients without any generalized or local side effects [13].

We have tested typical microorganisms as representative of either Gram-positive or Gram-negative aerobic bacteria often detected in human wounds and ulcers with slow tendency to heal. The experimental method that has been used was selected because other procedures (such as depositing the ozonated oil in small wells) did not reliably work due to the poor diffusion of ozonated oil throughout the medium. Reproducibility of results was excellent, and the experimental method closely reproduced the in vivo situation when the ozonated oil is applied (usually twice daily) on the ulcers.

One point that needs to be emphasized is that, before the oil application, the damaged skin surface must be cleaned by removing necrotic tissue, pus, loose fibrin deposition, and excess of fluid exudates. Such a cleaning operation can be done by curettage and washing the surface, preferably with ozonated water or diluted $\mathrm{H}_{2} \mathrm{O}_{2}$ solution, useful to eliminate most of the plasma proteins, hence antioxidants, which will limit the disinfection and the healing stimulation. How ozonated oil precisely acts remains a debatable question. According to the SEM results, the anti-infective activity is not dependent on structural alterations at the level of microorganisms. However, it seems likely that 1,2,4-trioxolane present in the ozonated oil, when added to the warm exudates film of the ulcer, slowly decomposes generating local oxygen, $\mathrm{H}_{2} \mathrm{O}_{2}$ as reactive oxygen species (ROS), and a trace of lipid oxidation products (4-HNE). Such a cascade can explain the prolonged disinfectant action and stimulation of proliferative activity of fibroblasts and keratinoblasts [12]. Other relevant questions are: (i) how much oil should be used? As the application is repeated every 12 hours, an oil layer of about $2 \mathrm{~mm}$ is enough; (ii) at what ozonation degree? The purpose of preparing a "weak", "medium", and "strong" oil reflects the need of treating either small, ample, or very infected ulcers. Thus, it is supposed that as an ulcer progressively improves, ozonated oil with lower grade of peroxide will be used.

It is unfortunate that the topical use of cleaning the ulcer and the application of ozonated oil remain mostly confined to a few countries which have become knowledgeable of 

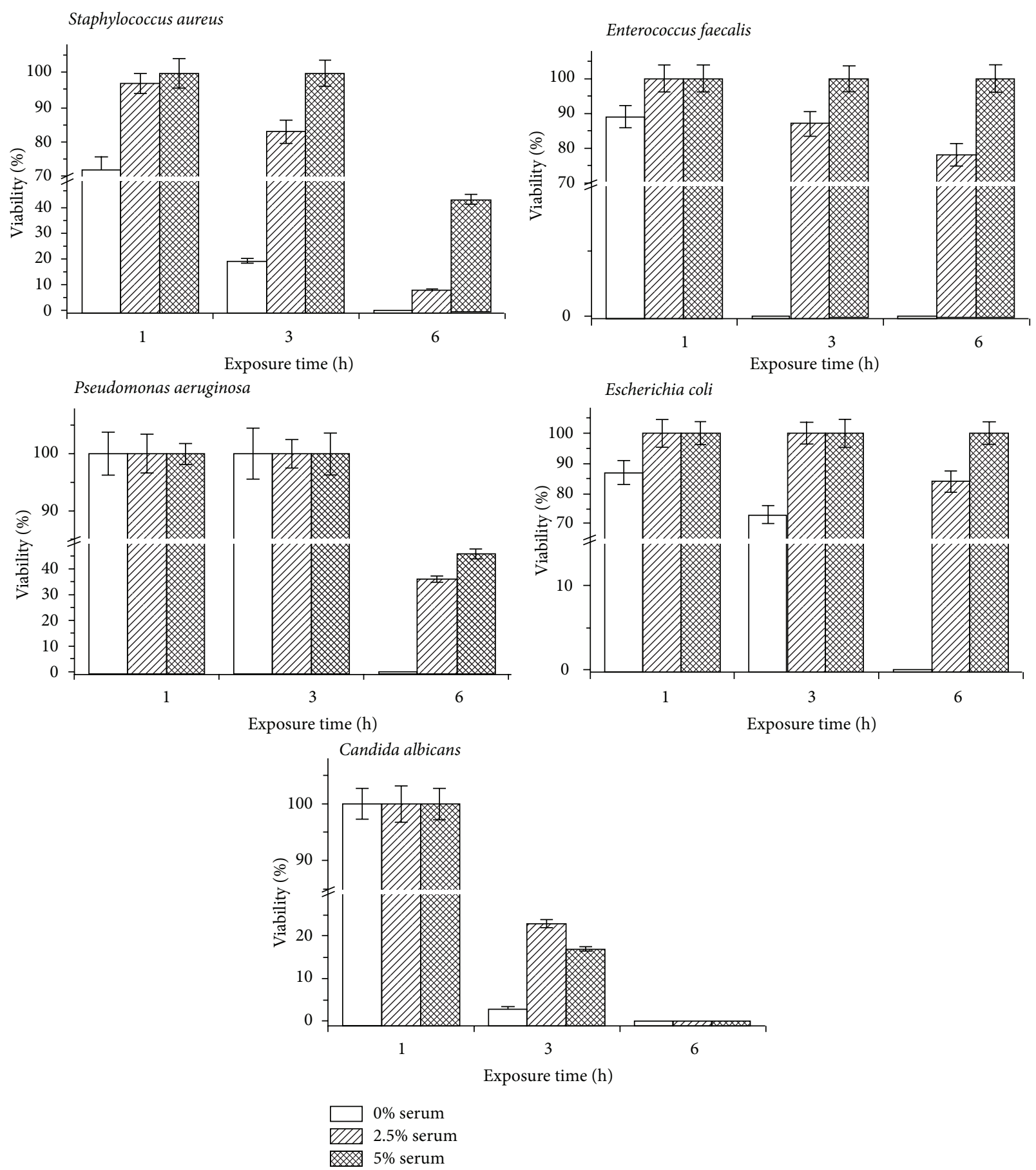

FIGURE 2: Viability of the treated cells with respect to the control after different exposure times to ozonated oil at the highest peroxide value either in the absence or in the presence of serum at different concentrations (see text for further details).

the ozone derivatives efficacy. Moreover, in most cases, the topical use takes place on the oil ozone derivative as such. Prospectively, it would be desirable to develop ointments characterized by both optimized skin permeability and safety upon open wounds. It is regrettable that the established medical community, which so far prefers to use antibiotic ointments in the absence or in the presence of growth factors or other methods [13], is not aware of the ozonated oil advantages as low-cost and great efficacy. As soon as it will be discovered, the topical treatment of torpid ulcers and wounds will be benefited by millions of patients, particularly in poor countries.

\section{Conflict of Interests}

The authors declare no conflict of interests. 


\section{References}

[1] M. Ingram and E. M. Barnes, "Sterilization by means of ozone," Journal of Applied Microbiology, vol. 17, pp. 246-271, 1954.

[2] A. Joss, H. Siegrist, and T. A. Ternes, "Are we about to upgrade wastewater treatment for removing organic micropollutants?" Water Science and Technology, vol. 57, no. 2, pp. 251-255, 2008.

[3] C. von Sonntag and U. von Gunten, Chemistry of Ozone in Water and Wastewater Treatment. From Basic Principles to Applications, Water Intelligence Online, IWA Publishing, 2012.

[4] D. Białoszewski, A. Pietruczuk-Padzik, A. Kalicinska et al., "Activity of ozonated water and ozone against staphylococcus aureus and pseudomonas aeruginosa bioflms," Medical Science Monitor, vol. 17, no. 11, pp. BR339-BR344, 2011.

[5] V. Bocci, I. Zanardi, and V. Travagli, "Oxygen/ozone as a medical gas mixture. A critical evaluation of the various methods clarifies positive and negative aspects," Medical Gas Research, vol. 1, article 6, 2011.

[6] V. Bocci, I. Zanardi, E. Borrelli, and V. Travagli, "Reliable and effective oxygen-ozone therapy at a crossroads with ozonated saline infusion and ozone rectal insufflation," Journal of Pharmacy and Pharmacology, vol. 64, no. 4, pp. 482-489, 2012.

[7] S. Burgassi, I. Zanardi, V. Travagli, E. Montomoli, and V. Bocci, "How much ozone bactericidal activity is compromised by plasma components?" Journal of Applied Microbiology, vol. 106, no. 5, pp. 1715-1721, 2009.

[8] M. Sagai and V. Bocci, "Mechanisms of action involved in ozone therapy: is healing induced via a mild oxidative stress?” Medical Gas Research, vol. 1, article 29, 2011.

[9] K. Skalska, S. Ledakowicz, J. Perkowski, and B. Sencio, "Germicidal properties of ozonated sunflower oil," Ozone: Science and Engineering, vol. 31, no. 3, pp. 232-237, 2009.

[10] A. Sega, I. Zanardi, L. Chiasserini, A. Gabbrielli, V. Bocci, and V. Travagli, "Properties of sesame oil by detailed ${ }^{1} \mathrm{H}$ and ${ }^{13} \mathrm{C}$ NMR assignments before and after ozonation and their correlation with iodine value, peroxide value, and viscosity measurements," Chemistry and Physics of Lipids, vol. 163, no. 2, pp. 148-156, 2010.

[11] V. Travagli, I. Zanardi, G. Valacchi, and V. Bocci, "Ozone and ozonated oils in skin diseases: a review," Mediators of Inflammation, vol. 2010, Article ID 610418, 9 pages, 2010.

[12] G. Valacchi, Y. Lim, G. Belmonte et al., "Ozonated sesame oil enhances cutaneous wound healing in SKH1 mice," Wound Repair and Regeneration, vol. 19, no. 1, pp. 107-115, 2011.

[13] G. Valacchi, I. Zanardi, C. Sticozzi, V. Bocci, and V. Travagli, "Emerging topics in cutaneous wound repair," Annals of the New York Academy of Sciences, vol. 1259, pp. 136-144, 2012.

[14] P. V. Patel, S. Kumar, G. D. Vidya, A. Patel, J. C. Holmes, and V. Kumar, "Cytological assessment of healing palatal donor site wounds and grafted gingival wounds after application of ozonated oil: an eighteen-month randomized controlled clinical trial," Acta Cytologica, vol. 56, pp. 277-284, 2012.

[15] S. Menéndez, L. Falcón, and Y. Maqueira, “Therapeutic efficacy of topical OLEOZON in patients suffering from onychomycosis," Mycoses, vol. 54, no. 5, pp. e272-e277, 2011.

[16] L. V. Guerrer, K. C. Cunha, M. C. L. Nogueira, C. C. Cardoso, Soares MMCN, and M. T. G. Almeida, "In vitro antifungal activity of ozonized sunflower oil on yeasts from onychomycosis," Brazilian Journal of Microbiology, vol. 43, pp. 1315-1318, 2012.

[17] N. R. de Almeida, A. Beatriz, A. C. Micheletti, and E. J. de Arruda, "Ozonized vegetable oils and therapeutic properties: a review," Orbital-The Electronic Journal of Chemistry, vol. 4, pp. 313-326, 2012.
[18] I. Zanardi, V. Travagli, A. Gabbrielli, L. Chiasserini, and V. Bocci, "Physico-chemical characterization of sesame oil derivatives," Lipids, vol. 43, no. 9, pp. 877-886, 2008.

[19] A. L. Erlandson Jr. and C. A. Lawrence, "Inactivating medium for hexachlorophene (G-11) types of compounds and some substituted phenolic disinfectants," Science, vol. 118, no. 3062, pp. 274-276, 1953.

[20] Y. Q. Zhang, Q.-P. Wu, J. M. Zhang, and X. H. Yang, "Effects of ozone on membrane permeability and ultrastructure in Pseudomonas aeruginosa," Journal of Applied Microbiology, vol. 111, no. 4, pp. 1006-1015, 2011.

[21] P. G. Bowler, B. I. Duerden, and D. G. Armstrong, "Wound microbiology and associated approaches to wound management," Clinical Microbiology Reviews, vol. 14, no. 2, pp. 244-269, 2001. 

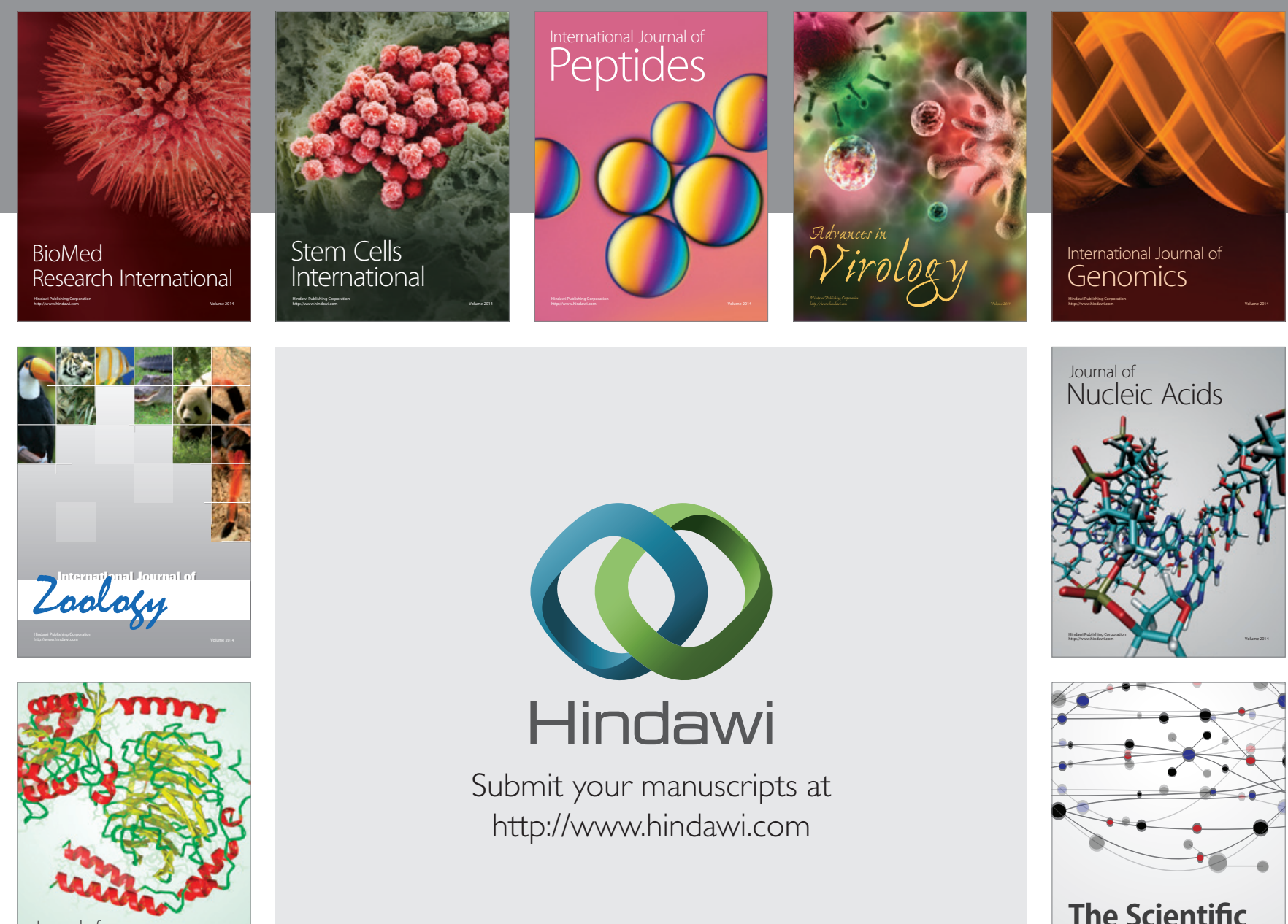

Submit your manuscripts at

http://www.hindawi.com

Journal of
Signal Transduction
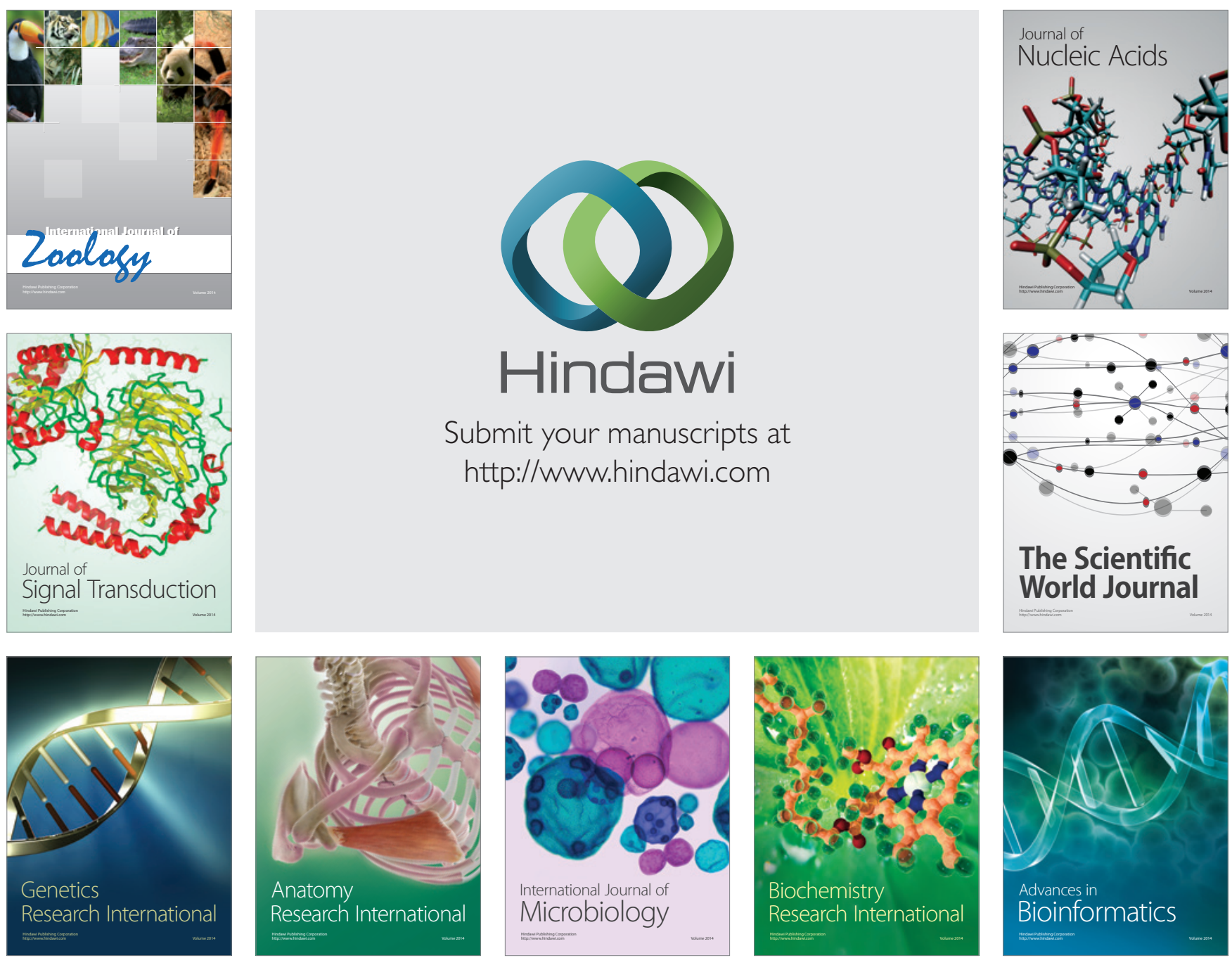

The Scientific World Journal
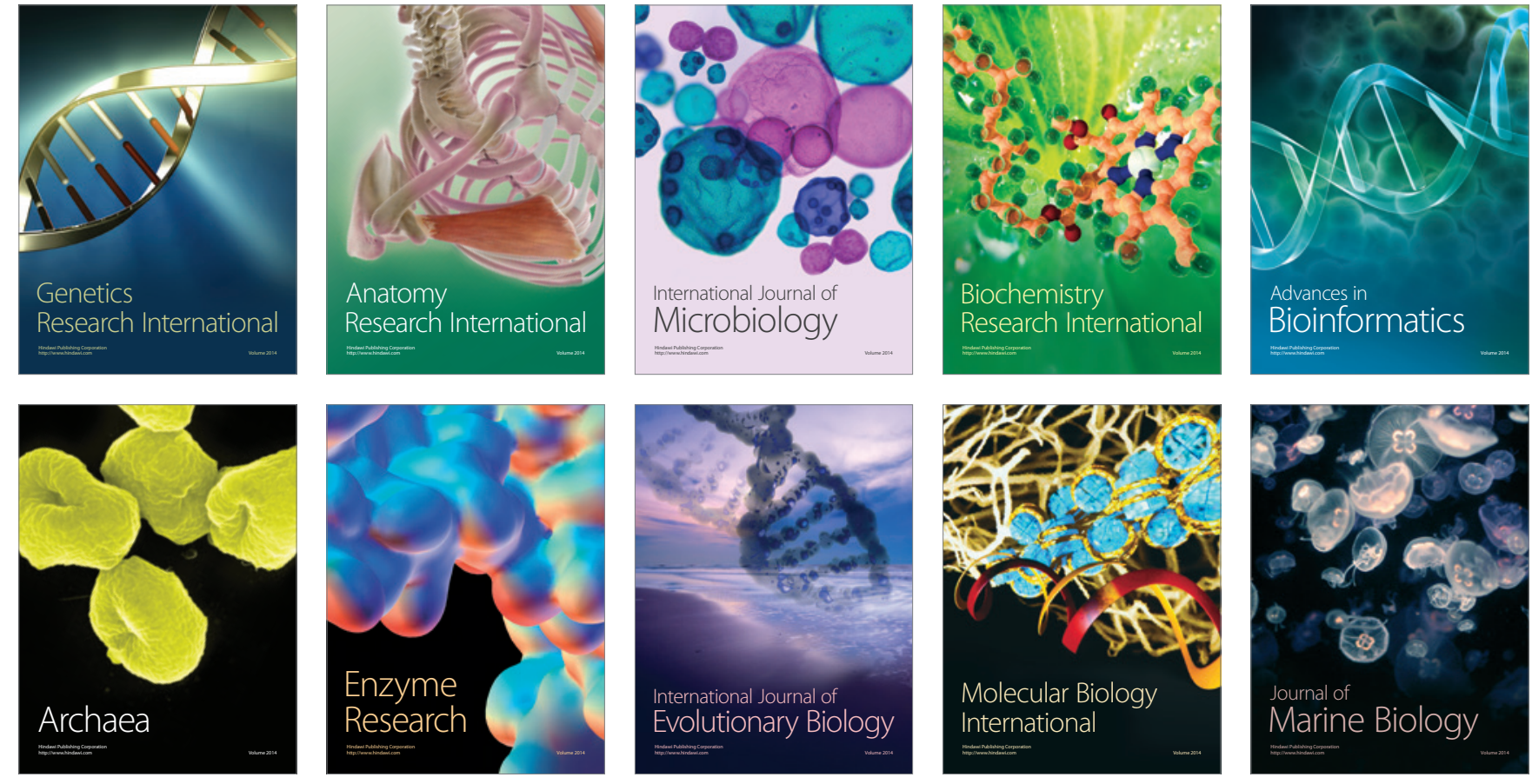